\title{
Neuroscience of Compulsive Eating Behavior
}

\author{
Catherine F. Moore ${ }^{1,2}$, Valentina Sabino ${ }^{1}$, George F. Koob ${ }^{3}$ and Pietro Cottone ${ }^{1 *}$ \\ ${ }^{1}$ Laboratory of Addictive Disorders, Departments of Pharmacology and Psychiatry, Boston University School of Medicine, \\ Boston, MA, United States, ${ }^{2}$ Graduate Program for Neuroscience, Boston University School of Medicine, Boston, MA, \\ United States, ${ }^{3}$ National Institute on Alcohol Abuse and Alcoholism, National Institutes of Health, Bethesda, MD, \\ United States
}

A systematic characterization of compulsivity in pathological forms of eating has been proposed in the context of three functional domains: (1) habitual overeating; (2) overeating to relieve a negative emotional state; and (3) overeating despite aversive consequences. In this review, we provide evidence supporting this hypothesis and we differentiate the nascent field of neurocircuits and neurochemical mediators of compulsive eating through their underlying neuropsychobiological processes. A better understanding of the neurobiological mechanisms that lead to compulsive eating behavior can improve behavioral and pharmacological intervention for disorders of pathological eating.

\section{OPEN ACCESS}

Edited by:

Carlo Cifani,

University of Camerino, Italy

Reviewed by:

Esther Aarts,

Radboud University Nijmegen,

Netherlands

Camila De Ávila Dal'Bo,

Laval University, Canada

*Correspondence:

Pietro Cottone

cottone@bu.edu

Specialty section

This article was submitted to Neuroenergetics, Nutrition and Brain

Health,

a section of the journal

Frontiers in Neuroscience

Received: 15 May 2017 Accepted: 08 August 2017

Published: 24 August 2017

Citation:

Moore CF, Sabino V, Koob GF and Cottone P (2017) Neuroscience of Compulsive Eating Behavior.

Front. Neurosci. 11:469. doi: 10.3389/fnins.2017.00469
Keywords: compulsive, addiction, eating, habit, withdrawal, inhibitory control

\section{INTRODUCTION}

Compulsivity, defined as a strong, irresistible internal drive to perform an action, typically contrary to one's will, is a transdiagnostic construct present in numerous psychiatric conditions. Compulsive eating behavior is observed in pathological forms of feeding behavior, such as binge eating disorder (BED), certain forms of obesity, and the recently proposed "food addiction" (Moore et al., 2017). BED is an eating disorder defined by uncontrolled overeating of palatable food (i.e., high in fat and/or sugar) in brief periods of time. "Food addiction" is a recently proposed concept measured by the "Yale Food Addiction Scale," which uses diagnostic criteria based on the Diagnostic and Statistical Manual (DSM-V) diagnosis of substance use disorder (American Psychiatric Association, 2013; Gearhardt et al., 2016). While compulsive eating behavior is highly prevalent in obese individuals, it is neither necessary nor sufficient to characterize obesity, an extremely heterogeneous disorder defined simply through having a body mass index (BMI) of $\geq 30$ (Curtis and Davis, 2014). Here, we review evidence from the literature supporting the dissection of compulsive eating into three main elements: (1) habitual overeating (Smith and Robbins, 2013; Tomasi and Volkow, 2013), (2) overeating to relieve a negative emotional state (Cottone et al., 2009a; Parylak et al., 2011), and (3) overeating despite aversive consequences (Cottone et al., 2012; Rossetti et al., 2014). In animal models, long-term access to palatable food results in compulsive-like habit formation, which results in negative emotion-like states and which is resistant to aversive consequences. It is important to note that the different elements of compulsive eating are not mutually exclusive, and can be attributed to distinct, though often intersecting, mechanisms.

\section{HABITUAL OVEREATING}

Goal-directed, voluntary actions can become compulsive, stimulus-driven habits through Pavlovian conditioning mechanisms. Habits are formed when the stimulus-response association 
overlaps the goal of the behavior (e.g., the palatable food or the drug); and the outcome/reward no longer motivates the action (Everitt and Robbins, 2016). This overlap occurs throughout repeated pairings, where reward-associated stimuli (e.g., advertising in humans, or a tone in animals) can elicit and maintain compulsive seeking behavior (Everitt and Robbins, 2016). An important element of compulsive habits is the inability to retain evaluative processes that can allow for the switch from stimulus-response driven back to goal-directed actions when the value of the reward is reduced (Watson et al., 2014; Horstmann et al., 2015). Therefore, habitual behavior can be assessed through outcome devaluation procedures, where persistence of responding is measured after the value of the outcome is decreased (i.e., drug/food reward).

There is evidence from both human and animal studies to suggest a link between binge eating/palatable food and an increased tendency to engage in habitual responding. Individuals with $\mathrm{BED}$ and/or obesity have been shown to display a bias toward habitual responding (Horstmann et al., 2015; Janssen et al., 2017) and the use of neural circuits that support these processes (Voon et al., 2015). In addition, palatable food consumption induced habitual responding in animals, observed as resistance to devaluation procedures (Kendig et al., 2013; Furlong et al., 2014; Reichelt et al., 2014; Figure 1A). Furthermore, in healthy weight controls, palatable food associated cues bias responding away from goal-directed actions toward habitual behavior, determined as continued cueelicited food seeking after satiation (i.e., resistance to devaluation; Watson et al., 2014). Obese and binge eating individuals showed heightened food cue reactivity and attentional biases (Carnell et al., 2014; Schmitz et al., 2014), which likely contribute to the initiation and the persistence of overeating.

The transition from reinforcement learning to habitual responding is hypothesized to be mediated by the striatum, an area composed of ventral (i.e., nucleus accumbens, NAc) and dorsal regions. While the NAc plays a key role in the reinforcing effects of food and drugs, the dorsal striatum is thought to contribute to the development of habits (Everitt and Robbins, 2016). Habit-learning processes, implicated in the shift to addiction, are accompanied by a concomitant shift from ventral to dorsal striatal circuits that control behavior. Food and associated cues increase extracellular dopamine transmission in the NAc, which is hypothesized to result in increased incentive salience and an enhancement of habit learning (Everitt and Robbins, 2016). Initially in reinforcement learning, which corresponds with early stages of drug use or palatable food consumption, dopamine signaling in the NAc drives goaldirected responding for the reward, and the pharmacological inactivation of the dorsal striatum has no effect. However, in later stages, when habitual responding eventually dominates, antagonizing dorsolateral striatal dopamine blocks compulsivelike responding and restores sensitivity to devaluation (Belin and Everitt, 2008). Research indicates heightened behavioral and/or neural responses to food cues in individuals with BED (Wang et al., 2011) and obesity (Stoeckel et al., 2008; Carnell et al., 2014), and behavioral and/or neural responses to food cues can predict subsequent food intake and weight gain (Demos et al., 2012; Lawrence et al., 2012). Dopamine2 receptor (D2R) binding potential in dorsal regions of the striatum was found to be positively associated with BMI and habitual, opportunistic eating (Guo et al., 2014) yet $\mathrm{D} 2 \mathrm{R}$ availability in the entire striatum has also been found to be lower in obese individuals (further discussed below; Volkow et al., 2008), likely reflecting dynamic and regional changes as habitual compulsive overeating evolves. For example, one interpretation of the decreased D2R availability is that dopamine function becomes compromised with repeated excessive activation, see below. This highlights the importance of researchers further associating neurobiological measures with behavioral indices of habitual compulsive overeating. In an animal model, long-term, intermittent access to palatable food was associated with greater activation of the dorsolateral striatum in rats (Figure 2A; Furlong et al., 2014). Thus, experience with palatable food causes neuroadaptations in striatal circuitry, which may, in turn, cause and potentiate compulsive, habitual overeating, and increase susceptibility to food cues.

\section{OVEREATING TO RELIEVE A NEGATIVE EMOTIONAL STATE}

In drug addiction, the transition from casual to compulsive drug use is hypothesized to reflect an allostatic change in mood, where drugs acquire negative reinforcing properties (Koob et al., 2014). Analogously, ingesting palatable food to alleviate a negative emotional state represents an element of compulsive eating behavior (Cottone et al., 2009a; Parylak et al., 2011). Two neuropsychobiological processes underlie this element: (i) decreased reward function, caused by within-system neuroadaptations and (ii) withdrawal-induced negative affect, caused by between-system neuroadaptations (Parylak et al., 2011; Koob et al., 2014). These processes are characterized by affective habituation and loss of motivation for ordinary life stimuli, as well as by dysphoria, irritability, and anxiety (Parylak et al., 2011; Koob et al., 2014). Through a negatively reinforced mechanism, compulsive eating would, therefore, "paradoxically" both improve the reward deficit and suppress negative emotions in the short term, but worsen them in the long term, a form of misregulation in self-regulation theory (Koob and Le Moal, 1997; Cottone et al., 2009a; Parylak et al., 2011).

The overeating of, and subsequent withdrawal from, palatable food is hypothesized to cause or contribute to the negative emotional state. In humans, there is evidence that dieting contributes to negative affect, which in turn predicts later increases in eating pathology (Stice, 2002). Indeed, consumption of palatable food, commonly referred to as "comfort food," can effectively mitigate acutely the physiological stress response and anxiety (Pecoraro et al., 2004; Tomiyama et al., 2011), thus compulsive eating behavior may be strengthened through negative reinforcing mechanisms. Similarly, in animal models, overconsumption of palatable diets has been shown to decrease brain reward system functioning; for example, decreases in 

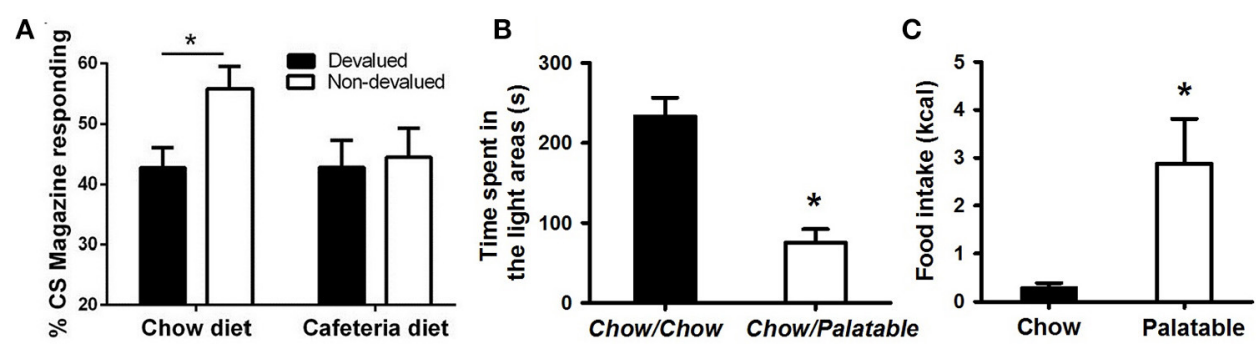

FIGURE 1 | Evidence of compulsive eating behavior in animal models. (A) Rats fed a cafeteria diet show resistance to devaluation procedures; from Reichelt et al. (2014). In this procedure, rats were fed continuously a high-fat cafeteria diet, consisting of four commercially available foods: half-sweet (cakes, cookies) and half-savory (pies, dim sims) items. After 2 weeks, rats were trained to consume sucrose deliveries (either cherry or grape flavored) paired with a stimulus (tone or noise, respectively). Following training, one of these sucrose solutions was devalued by specific satiety, where rats could drink one particular flavor ad libitum prior to testing. Head entries during sucrose-paired stimulation were measured for both the devalued and non-devalued flavor of sucrose. A decrease in head entries compared to the non-devalued condition indicates devaluation, or goal-directed behavior; whereas no decrease in head entries indicates habitual behavior. (B) Rats withdrawn from a highly palatable, chocolate diet display anxiety-like behaviors; adapted with permission from lemolo et al. (2013). In this paradigm, animals are either continuously fed a standard chow food ("Chow/Chow") or intermittently cycled between a standard chow food for 5 days and a highly-palatable, high-sucrose food for 2 days ("Chow/Palatable"). After chronic, intermittent palatable diet exposure rats were tested for anxiety-like behavior in a light/dark apparatus during withdrawal from chronic, intermittent access to the palatable diet. Shorter time spent in the light side of the apparatus indicates higher anxiety-like behavior compared to "Chow/Chow" control rats. (C) Food intake in rats with a history of intermittent access to palatable food is resistant to the aversiveness of a light/dark conflict test; adapted with permission from Ferragud et al. (2017). In this experiment, animals were trained in an operant chamber to self-administer food pellets that consisted of a standard chow food ("Chow") or a highly-palatable, high-sucrose food ("Palatable") for 1 h each day. Following escalation of palatable food responding, animals were tested for compulsive-like behavior in the light/dark conflict test. This test consists of a light/dark apparatus where a food cup containing the same food received during self-administration is positioned in the aversive, light compartment. "Compulsive-like eating" is operationalized as the amount of food eaten during the trial compared to control "Chow" conditions, where eating behavior is typically suppressed due to the aversiveness of the light compartment. ${ }^{*} p<0.05$ Bonferonni corrected.
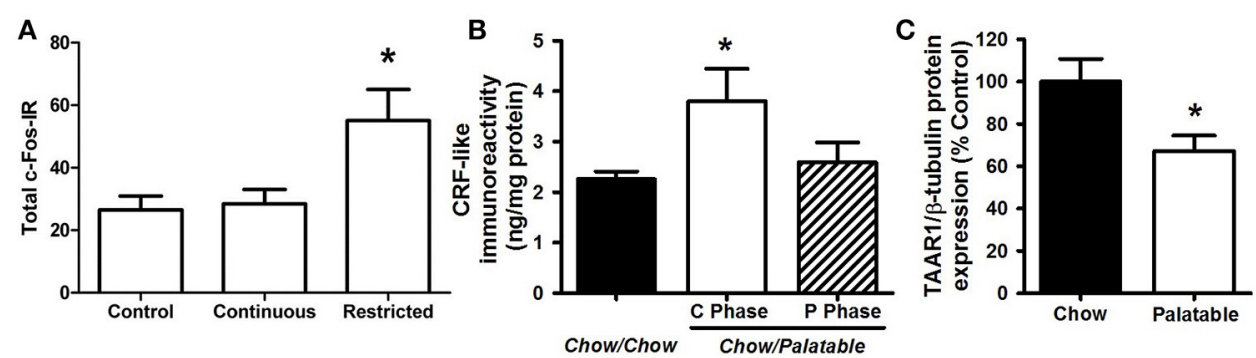

FIGURE 2 | Neurobiological substrates of compulsive eating behavior in animal models. (A) Rats that habitually overeat display increased activation of the dorsolateral striatum; from Furlong et al. (2014). In this procedure, rats were given either control chow only, or chow + continuous or restricted (2 h daily) access to palatable food, consisting of sweetened-condensed milk (22\% fat; $67 \%$ sugar, $10 \%$ protein). After 2 weeks, rats were tested in a devaluation procedure to assess habitual responding for food reward. The restricted access group displayed resistance to devaluation procedures, or habitual responding for palatable food, while control animals and the continuous access group retained goal-directed responding. Following this procedure, cFos immunoreactivity (cFos-IR) was quantified in the dorsolateral striatum, and habitually responding, restricted access rats displayed an increase in cFos IR compared to control and continuous access groups. (B) Rats withdrawn from a highly palatable, chocolate diet display increased CRF in the CeA; adapted with permission from Cottone et al. (2009a). In this paradigm, animals are either continuously fed a standard chow food ("Chow/Chow") or intermittently cycled between a standard chow food for 5 days and a highly-palatable, high-sucrose food for 2 days ("Chow/Palatable"). After chronic, intermittent palatable diet exposure rats display anxiety- and depressive-like behavior during withdrawal from palatable food. This negative emotional state is accompanied by an increase in CRF expression in the CeA of withdrawn rats. (C) Compulsive, binge eating rats have reduced TAAR1 expression in the PFC; adapted with permission from Ferragud et al. (2017). In this experiment, animals were trained in an operant chamber to self-administer food pellets that consisted of a standard chow food ("Chow") or a highly-palatable, high-sucrose food ("Palatable") for $1 \mathrm{~h}$ each day. Following escalation of palatable food responding, "Palatable" rats display compulsive-like eating in the light/dark conflict test, as well as a decrease in TAAR1 expression in the PFC. ${ }^{\star} p<0.05$.

brain-stimulation reward responsiveness in obese rats (Johnson and Kenny, 2010) and decreased motivation for rewards in animals with a history of prolonged palatable food consumption (Vendruscolo et al., 2010). During withdrawal from palatable food, the emergence of a negative emotional state, characterized by anxiety- and depressive-like behavior (Figure 1B; Iemolo et al., 2012) (Cottone et al., 2008; Sharma et al., 2013), and enhanced stress-responsiveness (Avena et al., 2008; Blasio et al., 2014a), is observed. When access to palatable food is renewed, subjects display compulsive-like eating (Avena et al., 2008; Cottone et al., 2009b; Rossetti et al., 2014) and withdrawalinduced anxiety- and depressive-like behaviors are paradoxically reversed (Iemolo et al., 2012). Thus, evidence suggests the emergence of a negative emotional state is induced by withdrawal from palatable food, and that compulsive eating behavior is driven by its ability to relieve such a state. 
Within-system neuroadaptations are hypothesized to occur during palatable food overconsumption, which may repeatedly stimulate and eventually desensitize the mesolimbic system, resulting in reward deficiency. There is evidence of reduced dopaminergic signaling in striatal regions of obese individuals, observed as lower D2R availability (Volkow et al., 2008), reduced neural response to consummatory food reward (Stice et al., 2008, 2010), and blunted amphetamine-induced dopamine release in the NAc (van de Giessen et al., 2014). High fat and high sugar diet exposure has been shown to alter dopaminergic signaling observed as downregulation of striatal D2Rs (Johnson and Kenny, 2010), decreases in baseline extracellular dopamine in the NAc (Zhang et al., 2015), and decreases in dopamine transporter expression and function (Hajnal and Norgren, 2002; Hryhorczuk et al., 2016). Thus, it is hypothesized that palatable food-related reward is diminished, and compulsive overeating reflects an attempt to reactivate a hypofunctional reward circuit (Wang et al., 2001; Geiger et al., 2009).

Between-system neuroadaptations are also hypothesized to cause the emergence of a negative emotional withdrawal state and are largely characterized by recruitment of stress systems in the extended amygdala (Koob et al., 2014), an area consisting of the central nucleus of the amygdala (CeA), the bed nucleus of the stria terminalis (BNST), and a transition area in the NAc shell. In the CeA, corticotropin-releasing factor (CRF) and its type-1 receptor (CRF1R) are recruited following extended access to palatable food (e.g., palatable food withdrawal-induced increases in CRF expression and CRF1R electrophysiological responsiveness) (Figure 2B; Cottone et al., 2009a) (Teegarden and Bale, 2007; Iemolo et al., 2013). Increased anxiety-like behavior observed during withdrawal is mediated by the CRFCRF1 system in the CeA (Cottone et al., 2009a; Iemolo et al., 2013), and renewed consumption of the palatable diet reverses both the withdrawal-dependent behaviors and the heightened CRF expression levels (Teegarden and Bale, 2007; Cottone et al., 2009a; Iemolo et al., 2013). In addition, stress-induced overconsumption of the palatable diet can be blocked by administration of CRF1R antagonists into the BNST (Micioni Di Bonaventura et al., 2014). These studies indicate a critical role for CRF-CRF1R system in both food withdrawal-like behavior and negative reinforcement-driven palatable food overconsumption.

During withdrawal, the endocannabinoid system is engaged, likely to compensate for the recruitment of the CRF-system, and acts to restore homeostasis in amygdalar circuits (Sidhpura and Parsons, 2011; Koob et al., 2014). The endocannabinoid system of the amygdala is hypothesized to serve as a "buffer system" to dampen the negative emotional state driven by withdrawal with food and drugs (Sidhpura and Parsons, 2011; Blasio et al., 2013; Koob et al., 2014). Indeed, withdrawal from palatable food recruited the endocannabinoid system in the $\mathrm{CeA}$, induced the upregulation of 2-arachidonoylglycerol (2$A G)$ and cannabinoid type-1 receptor (CB1R) (Blasio et al., 2013). Blocking CB1R with the inverse agonist rimonabant into the CeA precipitated anxiety-like behavior and hypophagia during palatable food withdrawal (Blasio et al., 2013, 2014a). Rimonabant is associated with an emergence of severe psychiatric side-effects in obese patients (Christensen et al., 2007), which we hypothesize may be due to a precipitation of a withdrawallike syndrome in a subpopulation of obese individuals abstaining from palatable food as they attempt to lose weight (e.g., by dieting).

\section{OVEREATING DESPITE AVERSIVE CONSEQUENCES}

In drug addiction, loss of control over behavior concerning the drug-seeking or taking in spite of negative consequences represents one of the elements of compulsivity associated with the disorder (Koob and Volkow, 2010; American Psychiatric Association, 2013). Similarly, in many forms of pathological eating, both humans and animals will fail to suppress food seeking and taking in adverse conditions where behaviors would be inhibited (Oswald et al., 2011; Curtis and Davis, 2014; Dore et al., 2014; Velazquez-Sanchez et al., 2014). In humans, negative consequences associated with overeating include social impairment, emotional disturbances, psychiatric disorders, and life-threatening medical conditions associated with weight gain. In animal models, this element of compulsivity is observed as continued consumption of palatable food even when associated with an adverse physical or emotional consequence (e.g., eating while receiving a footshock, or eating in an aversive environment; Figure 1C; Ferragud et al., 2017) (Oswald et al., 2011; Cottone et al., 2012; Curtis and Davis, 2014; Rossetti et al., 2014; Velazquez-Sanchez et al., 2015). This element of continued overeating despite aversive consequences is characterized by failure of inhibitory control processes contributing to a loss of control over eating behavior. Indeed, high trait impulsive action (i.e., inability to withhold a response) has been shown to predict compulsive-like eating behavior (Velazquez-Sanchez et al., 2014).

Inhibitory control over behavior is largely regulated by the prefrontal cortex (PFC), and dysfunctions in cortico-striatal circuitries are thought to underlie compulsive eating behaviors (Volkow et al., 2013). In addictive disorders, it is hypothesized that in one functional domain, PFC areas are hyper-responsive to food cues, resulting in high levels of craving. In a separate functional domain, a general hypo-activation of prefrontal circuits involved in inhibitory control results in impulsivity, incentive salience and reengagement of habit systems via the disinhibition of the basal ganglia and negative emotional states via disinhibition of the stress systems of the amygdala (Koob and Volkow, 2016). The two opposing systems have been conceptualized as a "GO" system (dorsolateral PFC, anterior cingulate cortex, and orbitofrontal cortex), which is sensitized in compulsive eating, and a "STOP" system (ventromedial PFC), which is impaired in compulsive eating (Koob and Volkow, 2016). Abnormalities of the PFC are observed in individuals with BED and some forms of obesity. For instance, decreased baseline activity (Volkow et al., 2008) and enhanced food-cue induced activation (Dimitropoulos et al., 2012) is observed in prefrontal cortical areas of obese individuals; and higher BMI has been linked with diminished PFC activity during regulation of palatable food craving (Giuliani et al., 2014; Silvers et al., 2014). Medial prefrontal dysregulation is associated with deficits 
in inhibitory control (Batterink et al., 2010; Balodis et al., 2013; Hege et al., 2015) and impaired dietary restraint in individuals with BED (Balodis et al., 2013). Furthermore, lower functional connectivity between $\mathrm{dmPFC}$ and amygdalar brain regions was found to be associated with higher disinhibited eating behavior (Dietrich et al., 2016).

Multiple neurotransmitter systems in the PFC are involved in the emergence of compulsive eating behavior, including muopioid (MOR), Sigma 1 receptors $\left(\mathrm{Sig}_{1} \mathrm{R}\right)$, and Trace AmineAssociated Receptor 1 (TAAR1) (Blasio et al., 2014b; VelazquezSanchez et al., 2014; Selleck et al., 2015; Smith et al., 2015; Ferragud et al., 2017). In animal models of compulsivelike eating, limited access to a palatable diet resulted in the altered expression of genes coding for the opioid peptides proopiomelanocortin (POMC) and pro-dynorphin (PDyn; increased and decreased, respectively) in the medial PFC; in addition, site specific injection of naltrexone, a non-selective opioid receptor antagonist, into the $\mathrm{PFC}$ was able to reduce bingelike eating (Blasio et al., 2014b). In binge eating humans, treatment with a MOR antagonist reduced consumption of palatable food (Ziauddeen et al., 2013), motivation for high calorie food stimuli (Cambridge et al., 2013), and hedonic responses toward a sweet food reward (Ziauddeen et al., 2013). Similarly, in animal studies, the $\operatorname{Sig}_{1} \mathrm{R}$, a receptor involved in alcohol and drug reinforcement (Sabino et al., 2009, 2017), was upregulated in prefrontal cortical brain regions following limited access to a palatable diet, and peripheral administration of a $\operatorname{Sig}_{1} \mathrm{R}$ antagonist blocked binge and compulsive-like eating (Cottone et al., 2012). TAAR1, a receptor expressed in the striatum and prefrontal cortices is activated by trace amines and has been shown to modulate cortical glutamate and dopaminergic transmission (Leo et al., 2014; Espinoza et al., 2015). Protein expression of TAAR1 is decreased in the medial PFC of compulsive-like, binge-eating rats, and TAAR1 agonism injected into the infralimbic cortex blocked excessive intake of palatable food (Figure 2C; Ferragud et al., 2017). TAAR1 agonism also improved perseverative behavior and impulsivity (Espinoza et al., 2015), thus its effects on compulsive-like eating are likely occurring through restoring a loss of function of the "STOP" system. Prefrontal neurotransmitter systems are thought to influence compulsive behavior through the modulation of glutamatergic signaling in cortico-striatal pathways (Kalivas and Volkow, 2005; Cottone et al., 2012). Indeed, prolonged access to palatable food resulted in dysregulated glutamatergic plasticity of NAc neurons (Brown et al., 2015): accordingly, the uncompetitive antagonist of glutamate $\mathrm{N}$-methyl-D-aspartate glutamate receptors (NMDARs) memantine, which was shown to effectively reduce alcohol and drug reward/reinforcement (Popik et al., 2003; Sabino et al., 2013), reduced binge-like eating when microinfused directly into the NAc (Smith et al., 2015).

\section{CONCLUSIONS}

The field of mental health is moving toward a transdiagnostic approach to understanding the neurobiological mechanisms underlying psychiatric disorders. At the National Institutes of Health, a Research Domain Criteria (RDoC) initiative by The National Institute of Mental Health is concentrating efforts into the identification of key domains of function common to multiple disorders (The National Institute of Mental Health, 2013). For example, in addiction disorders, an Addiction Neuroclinical Assessment Framework has been proposed that incorporates the 3 major functional domains derived from the neurocircuitry of addiction: Incentive salience, Negative Emotionality, and Executive function (Kwako et al., 2016). Here, measurement of these domains in epidemiologic, genetic, clinical, and treatment studies are hypothesized to provide ultimately a reconceptualization of the nosology of addiction disorders for better prevention and treatment (Kwako et al., 2016).

Under this perspective, a better understanding of the construct of compulsive eating is warranted. Within the preclinical field, development and use of appropriate animal models that adequately model these functional domains is critical. Modeling complex behavioral constructs, such as those as presented in this review, may lead understanding of the development and progression of underlying neurobiological processes of the elements of compulsive eating behavior. Knowledge of the vulnerability factors, neuroadaptive mechanisms, and their interactions that lead to compulsive eating behavior has the potential to significantly improve behavioral and pharmacological intervention for millions of people.

\section{AUTHOR CONTRIBUTIONS}

All authors made substantial contributions to conception and design of this review. CM drafted the manuscript. VS, GK, and PC substantially and critically revised it for intellectual content. All authors gave final approval for its submission.

\section{ACKNOWLEDGMENTS}

This work was supported by the National Institutes of Health [grant numbers DA030425 (PC), MH091945 (PC), and MH093650 (VS)]; the Peter Paul Career Development Professorship (PC); the McManus Charitable Trust (VS); the Burroughs Wellcome Fund (CM) through the Transformative Training Program in Addiction Sciences. Its contents are solely the responsibility of the authors and do not necessarily represent the official views of the National Institutes of Health.

\section{REFERENCES}

American Psychiatric Association (2013). Diagnostic and Statistical Manual of Mental Disorders, 5th Ed $n$. Washington, DC: American Psychiatric Association.

Avena, N. M., Bocarsly, M. E., Rada, P., Kim, A., and Hoebel, B. G. (2008). After daily bingeing on a sucrose solution, food deprivation induces anxiety and accumbens dopamine/acetylcholine imbalance. Physiol. Behav. 94, 309-315. doi: 10.1016/j.physbeh.2008. 01.008 
Balodis, I. M., Molina, N. D., Kober, H., Worhunsky, P. D., White, M. A., Rajita, S., et al. (2013). Divergent neural substrates of inhibitory control in binge eating disorder relative to other manifestations of obesity. Obesity 21, 367-377. doi: 10.1002/oby.20068

Batterink, L., Yokum, S., and Stice, E. (2010). Body mass correlates inversely with inhibitory control in response to food among adolescent girls: an fMRI study. Neuroimage 52, 1696-1703. doi: 10.1016/j.neuroimage.2010.05.059

Belin, D., and Everitt, B. J. (2008). Cocaine seeking habits depend upon dopaminedependent serial connectivity linking the ventral with the dorsal striatum. Neuron 57, 432-441. doi: 10.1016/j.neuron.2007.12.019

Blasio, A., Iemolo, A., Sabino, V., Petrosino, S., Steardo, L., Rice, K. C., et al. (2013). Rimonabant precipitates anxiety in rats withdrawn from palatable food: role of the central amygdala. Neuropsychopharmacology 38, 2498-2507. doi: $10.1038 /$ npp.2013.153

Blasio, A., Rice, K. C., Sabino, V., and Cottone, P. (2014a). Characterization of a shortened model of diet alternation in female rats: effects of the CB1 receptor antagonist rimonabant on food intake and anxiety-like behavior. Behav. Pharmacol. 25, 609-617. doi: 10.1097/FBP.00000000000 00059

Blasio, A., Steardo, L., Sabino, V., and Cottone, P. (2014b). Opioid system in the medial prefrontal cortex mediates binge-like eating. Addict. Biol. 19, 652-662. doi: 10.1111/adb.12033

Brown, R. M., Kupchik, Y. M., Spencer, S., Garcia-Keller, C., Spanswick, D. C., Lawrence, A. J., et al. (2015). Addiction-like synaptic impairments in diet-induced obesity. Biol. Psychiatry 81, 797-806. doi: 10.1016/j.biopsych.2015.11.019

Cambridge, V. C., Ziauddeen, H., Nathan, P. J., Subramaniam, N., Dodds, C., Chamberlain, S. R., et al. (2013). Neural and behavioral effects of a novel mu opioid receptor antagonist in binge-eating obese people. Biol. Psychiatry 73, 887-894. doi: 10.1016/j.biopsych.2012.10.022

Carnell, S., Benson, L., Pantazatos, S. P., Hirsch, J., and Geliebter, A. (2014). Amodal brain activation and functional connectivity in response to high-energy-density food cues in obesity. Obesity 22, 2370-2378. doi: 10.1002/oby.20859

Christensen, R., Kristensen, P. K., Bartels, E. M., Bliddal, H., and Astrup, A. V. (2007). [A meta-analysis of the efficacy and safety of the anti-obesity agent Rimonabant]. Ugeskr. Laeg. 169, 4360-4363.

Cottone, P., Sabino, V., Roberto, M., Bajo, M., Pockros, L., Frihauf, J. B., et al. (2009a). CRF system recruitment mediates dark side of compulsive eating. Proc. Natl. Acad. Sci. U.S.A. 106, 20016-20020. doi: 10.1073/pnas.0908789106

Cottone, P., Sabino, V., Steardo, L., and Zorrilla, E. P. (2008). Opioid-dependent anticipatory negative contrast and binge-like eating in rats with limited access to highly preferred food. Neuropsychopharmacology 33, 524-535. doi: 10.1038/sj.npp.1301430

Cottone, P., Sabino, V., Steardo, L., and Zorrilla, E. P. (2009b). Consummatory, anxiety-related and metabolic adaptations in female rats with alternating access to preferred food. Psychoneuroendocrinology 34, 38-49. doi: 10.1016/j.psyneuen.2008.08.010

Cottone, P., Wang, X., Park, J. W., Valenza, M., Blasio, A., Kwak, J., et al. (2012). Antagonism of sigma-1 receptors blocks compulsive-like eating. Neuropsychopharmacology 37, 2593-2604. doi: 10.1038/npp.2012.89

Curtis, C., and Davis, C. (2014). A qualitative study of binge eating and obesity from an addiction perspective. Eating Disord. 22, 19-32. doi: 10.1080/10640266.2014.857515

Demos, K. E., Heatherton, T. F., and Kelley, W. M. (2012). Individual differences in nucleus accumbens activity to food and sexual images predict weight gain and sexual behavior. J. Neurosci. 32, 5549-5552. doi: 10.1523/JNEUROSCI.5958-11.2012

Dietrich, A., Hollmann, M., Mathar, D., Villringer, A., and Horstmann, A. (2016). Brain regulation of food craving: relationships with weight status and eating behavior. Int. J. Obes. 40, 982-989. doi: 10.1038/ijo.2016.28

Dimitropoulos, A., Tkach, J., Ho, A., and Kennedy, J. (2012). Greater corticolimbic activation to high-calorie food cues after eating in obese vs. normal-weight adults. Appetite 58, 303-312. doi: 10.1016/j.appet.2011.10.014

Dore, R., Valenza, M., Wang, X., Rice, K. C., Sabino, V., and Cottone, P. (2014). The inverse agonist of CB1 receptor SR141716 blocks compulsive eating of palatable food. Addict. Biol. 19, 849-861. doi: 10.1111/adb.12056
Espinoza, S., Lignani, G., Caffino, L., Maggi, S., Sukhanov, I., Leo, D., et al. (2015). TAAR1 modulates cortical glutamate NMDA receptor function. Neuropsychopharmacology 40, 2217-2227. doi: 10.1038/npp. 2015.65

Everitt, B. J., and Robbins, T. W. (2016). Drug addiction: updating actions to habits to compulsions ten years on. Annu. Rev. Psychol. 67, 23-50. doi: 10.1146/annurev-psych-122414-033457

Ferragud, A., Howell, A. D., Moore, C. F., Ta, T. L., Hoener, M. C., Sabino, V., et al. (2017). The trace amine-associated receptor 1 agonist RO5256390 blocks compulsive, Binge-Like eating in rats. Neuropsychopharmacology 42, 1458-1470. doi: 10.1038/npp.2016.233

Furlong, T. M., Jayaweera, H. K., Balleine, B. W., and Corbit, L. H. (2014). Bingelike consumption of a palatable food accelerates habitual control of behavior and is dependent on activation of the dorsolateral striatum. J. Neurosci. 34, 5012-5022. doi: 10.1523/JNEUROSCI.3707-13.2014

Gearhardt, A. N., Corbin, W. R., and Brownell, K. D. (2016). Development of the yale food addiction scale version 2.0. Psychol. Addict. Behav. 30, 113-121. doi: $10.1037 /$ adb0000136

Geiger, B. M., Haburcak, M., Avena, N. M., Moyer, M. C., Hoebel, B. G., and Pothos, E. N. (2009). Deficits of mesolimbic dopamine neurotransmission in rat dietary obesity. Neuroscience 159, 1193-1199. doi: 10.1016/j.neuroscience.2009.02.007

Giuliani, N. R., Mann, T., Tomiyama, A. J., and Berkman, E. T. (2014). Neural systems underlying the reappraisal of personally craved foods. J. Cogn. Neurosci. 26, 1390-1402. doi: 10.1162/jocn_a_00563

Guo, J., Simmons, W. K., Herscovitch, P., Martin, A., and Hall, K. D. (2014). Striatal dopamine D2-like receptor correlation patterns with human obesity and opportunistic eating behavior. Mol. Psychiatry 19, 1078-1084. doi: $10.1038 / \mathrm{mp} .2014 .102$

Hajnal, A., and Norgren, R. (2002). Repeated access to sucrose augments dopamine turnover in the nucleus accumbens. Neuroreport 13, 2213-2216. doi: 10.1097/00001756-200212030-00010

Hege, M. A., Stingl, K. T., Kullmann, S., Schag, K., Giel, K. E., Zipfel, S., et al. (2015). Attentional impulsivity in binge eating disorder modulates response inhibition performance and frontal brain networks. Int. J. Obes. 39, 353-360. doi: 10.1038/ijo.2014.99

Horstmann, A., Dietrich, A., Mathar, D., Possel, M., Villringer, A., and Neumann, J. (2015). Slave to habit? Obesity is associated with decreased behavioural sensitivity to reward devaluation. Appetite 87, 175-183. doi: 10.1016/j.appet.2014.12.212

Hryhorczuk, C., Florea, M., Rodaros, D., Poirier, I., Daneault, C., Des Rosiers, C., et al. (2016). Dampened mesolimbic dopamine function and signaling by saturated but not monounsaturated dietary lipids. Neuropsychopharmacology 41, 811-821. doi: 10.1038/npp.2015.207

Iemolo, A., Blasio, A., St. Cyr, S. A., Jiang, F., Rice, K. C., Sabino, V., et al. (2013). CRF-CRF1 receptor system in the central and basolateral nuclei of the amygdala differentially mediates excessive eating of palatable food. Neuropsychopharmacology $38, \quad 2456-2466$. doi: 10.1038/npp.20 13.147

Iemolo, A., Valenza, M., Tozier, L., Knapp, C. M., Kornetsky, C., Steardo, L., et al. (2012). Withdrawal from chronic, intermittent access to a highly palatable food induces depressive-like behavior in compulsive eating rats. Behav. Pharmacol. 23, 593-602. doi: 10.1097/FBP.0b013e328357697f

Janssen, L. K., Duif, I., van Loon, I., Wegman, J., de Vries, J. H., Cools, R., et al. (2017). Loss of lateral prefrontal cortex control in food-directed attention and goal-directed food choice in obesity. Neuroimage 146, 148-156. doi: 10.1016/j.neuroimage.2016.11.015

Johnson, P. M., and Kenny, P. J. (2010). Dopamine D2 receptors in addictionlike reward dysfunction and compulsive eating in obese rats. Nat. Neurosci. 13, 635-641. doi: 10.1038/nn.2519

Kalivas, P. W., and Volkow, N. D. (2005). The neural basis of addiction: a pathology of motivation and choice. Am. J. Psychiatry 162, 1403-1413. doi: 10.1176/appi.ajp.162.8.1403

Kendig, M. D., Boakes, R. A., Rooney, K. B., and Corbit, L. H. (2013). Chronic restricted access to $10 \%$ sucrose solution in adolescent and young adult rats impairs spatial memory and alters sensitivity to outcome devaluation. Physiol. Behav. 120, 164-172. doi: 10.1016/j.physbeh.2013.08.012 
Koob, G. F., and Le Moal, M. (1997). Drug abuse: hedonic homeostatic dysregulation. Science 278, 52-58. doi: 10.1126/science.278.5335.52

Koob, G. F., and Volkow, N. D. (2010). Neurocircuitry of addiction. Neuropsychopharmacology 35, 217-238. doi: 10.1038/npp.2009.110

Koob, G. F., and Volkow, N. D. (2016). Neurobiology of addiction: a neurocircuitry analysis lancet psychiatry. 3, 760-773. doi: 10.1016/S2215-0366(16)00104-8

Koob, G. F., Buck, C. L., Cohen, A., Edwards, S., Park, P. E., Schlosburg, J. E., et al. (2014). Addiction as a stress surfeit disorder. Neuropharmacology $76(\mathrm{Pt}$ B), 370-382. doi: 10.1016/j.neuropharm.2013.05.024

Kwako, L. E., Momenan, R., Litten, R. Z., Koob, G. F., and Goldman, D. (2016). Addictions neuroclinical assessment: a neurosciencebased framework for addictive disorders. Biol. Psychiatry 80, 179-189. doi: $10.1016 /$ j.biopsych.2015.10.024

Lawrence, N. S., Hinton, E. C., Parkinson, J. A., and Lawrence, A. D, (2012). Nucleus accumbens response to food cues predicts subsequent snack consumption in women and increased body mass index in those with reduced self-control. Neuroimage 63, 415-422. doi: 10.1016/j.neuroimage.2012.06.070

Leo, D., Mus, L., Espinoza, S., Hoener, M. C., Sotnikova, T. D., and Gainetdinov, R. R. (2014). Taar1-mediated modulation of presynaptic dopaminergic neurotransmission: role of D2 dopamine autoreceptors. Neuropharmacology 81, 283-291. doi: 10.1016/j.neuropharm.2014.02.007

Micioni Di Bonaventura, M. V., Ciccocioppo, R., Romano, A., Bossert, J. M., Rice, K. C., Ubaldi, M., et al. (2014). Role of bed nucleus of the stria terminalis corticotrophin-releasing factor receptors in frustration stress-induced bingelike palatable food consumption in female rats with a history of food restriction. J. Neurosci. 34, 11316-11324. doi: 10.1523/JNEUROSCI.1854-14.2014

Moore, C. F., Sabino, V., Koob, G. F., and Cottone, P. (2017). Pathological overeating: emerging evidence for a compulsivity construct. Neuropsychopharmacology 42, 1375-1389. doi: 10.1038/npp.2016.269

Oswald, K. D., Murdaugh, D. L., King, V. L., and Boggiano, M. M. (2011). Motivation for palatable food despite consequences in an animal model of binge eating. Int. J. Eat. Disord. 44, 203-211. doi: 10.1002/eat.20808

Parylak, S. L., Koob, G. F., and Zorrilla, E. P. (2011). The dark side of food addiction. Physiol. Behav. 104, 149-156. doi: 10.1016/j.physbeh.2011.04.063

Pecoraro, N., Reyes, F., Gomez, F., Bhargava, A., and Dallman, M. F. (2004). Chronic stress promotes palatable feeding, which reduces signs of stress: feedforward and feedback effects of chronic stress. Endocrinology 145, 3754-3762. doi: 10.1210/en.2004-0305

Popik, P., Kozela, E., Wrobel, M., Wozniak, K. M., and Slusher, B. S. (2003). Morphine tolerance and reward but not expression of morphine dependence are inhibited by the selective glutamate carboxypeptidase II (GCP II, NAALADase) inhibitor, 2-PMPA. Neuropsychopharmacology 28, 457-467. doi: 10.1038/sj.npp.1300048

Reichelt, A. C., Morris, M. J., and Westbrook, R. F. (2014). Cafeteria diet impairs expression of sensory-specific satiety and stimulus-outcome learning. Front. Psychol. 5:852. doi: 10.3389/fpsyg.2014.00852

Rossetti, C., Spena, G., Halfon, O., and Boutrel, B. (2014). Evidence for a compulsive-like behavior in rats exposed to alternate access to highly preferred palatable food. Addict. Biol. 19, 975-985. doi: 10.1111/adb.12065

Sabino, V., Cottone, P., Zhao, Y., Steardo, L., Koob, G. F., and Zorrilla, E. P. (2009). Selective reduction of alcohol drinking in Sardinian alcohol-preferring rats by a sigma-1 receptor antagonist. Psychopharmacology 205, 327-335. doi: 10.1007/s00213-009-1548-x

Sabino, V., Hicks, C., and Cottone, P. (2017). Sigma receptors and substance use disorders. Adv. Exp. Med. Biol. 964, 177-199. doi: 10.1007/978-3-319-50174-1_13

Sabino, V., Narayan, A. R., Zeric, T., Steardo, L., and Cottone, P. (2013). mTOR activation is required for the anti-alcohol effect of ketamine, but not memantine, in alcohol-preferring rats. Behav. Brain Res. 247, 9-16. doi: 10.1016/j.bbr.2013.02.030

Schmitz, F., Naumann, E., Trentowska, M., and Svaldi, J. (2014). Attentional bias for food cues in binge eating disorder. Appetite 80, 70-80. doi: 10.1016/j.appet.2014.04.023

Selleck, R. A., Lake, C., Estrada, V., Riederer, J., Andrzejewski, M., Sadeghian, K., et al. (2015). Endogenous opioid signaling in the medial prefrontal cortex is required for the expression of hunger-induced impulsive action. Neuropsychopharmacology 40, 2464-2474. doi: 10.1038/npp.2015.97
Sharma, S., Fernandes, M. F., and Fulton, S. (2013). Adaptations in brain reward circuitry underlie palatable food cravings and anxiety induced by high-fat diet withdrawal. Int. J. Obes. (London) 37, 1183-1191. doi: 10.1038/ijo.2012.197

Sidhpura, N., and Parsons, L. H. (2011). Endocannabinoid-mediated synaptic plasticity and addiction-related behavior. Neuropharmacology 61, 1070-1087. doi: 10.1016/j.neuropharm.2011.05.034

Silvers, J. A., Insel, C., Powers, A., Franz, P., Weber, J., Mischel, W., et al. (2014). Curbing craving: behavioral and brain evidence that children regulate craving when instructed to do so but have higher baseline craving than adults. Psychol. Sci. 25, 1932-1942. doi: 10.1177/0956797614546001

Smith, D. G., and Robbins, T. W. (2013). The neurobiological underpinnings of obesity and binge eating: a rationale for adopting the food addiction model. Biol. Psychiatry 73, 804-810. doi: 10.1016/j.biopsych.2012.08.026

Smith, K. L., Rao, R. R., Velazquez-Sanchez, C., Valenza, M., Giuliano, C., Everitt, B. J., et al. (2015). The uncompetitive N-methyl-D-aspartate antagonist memantine reduces binge-like eating, food-seeking behavior, and compulsive eating: role of the nucleus accumbens shell. Neuropsychopharmacology 40, 1163-1171. doi: 10.1038/npp.2014.299

Stice, E. (2002). Risk and maintenance factors for eating pathology: a meta-analytic review. Psychol. Bull. 128, 825-848. doi: 10.1037/0033-2909.128.5.825

Stice, E., Spoor, S., Bohon, C., and Small, D. M. (2008). Relation between obesity and blunted striatal response to food is moderated by TaqIA A1 allele. Science 322, 449-452. doi: 10.1126/science. 1161550

Stice, E., Yokum, S., Blum, K., and Bohon, C. (2010). Weight gain is associated with reduced striatal response to palatable food. J. Neurosci. 30, 13105-13109. doi: 10.1523/JNEUROSCI.2105-10.2010

Stoeckel, L. E., Weller, R. E., Cook, E. W. III, Twieg, D. B., Knowlton, R. C., and Cox, J. E. (2008). Widespread reward-system activation in obese women in response to pictures of high-calorie foods. Neuroimage 41, 636-647. doi: 10.1016/j.neuroimage.2008.02.031

Teegarden, S. L., and Bale, T. L. (2007). Decreases in dietary preference produce increased emotionality and risk for dietary relapse. Biol. Psychiatry 61, 1021-1029. doi: 10.1016/j.biopsych.2006.09.032

The National Institute of Mental Health (2013). Research Domain Criteria (RDoC).

Tomasi, D., and Volkow, N. D. (2013). Striatocortical pathway dysfunction in addiction and obesity: differences and similarities. Crit. Rev. Biochem. Mol. Biol. 48, 1-19. doi: 10.3109/10409238.2012.735642

Tomiyama, A. J., Dallman, M. F., and Epel, E. S. (2011). Comfort food is comforting to those most stressed: evidence of the chronic stress response network in high stress women. Psychoneuroendocrinology 36, 1513-1519. doi: 10.1016/j.psyneuen.2011.04.005

van de Giessen, E., Celik, F., Schweitzer, D. H., van den Brink, W., and Booij, J. (2014). Dopamine D2/3 receptor availability and amphetamineinduced dopamine release in obesity. J. Psychopharmacol. 28, 866-873. doi: $10.1177 / 0269881114531664$

Velazquez-Sanchez, C., Ferragud, A., Moore, C. F., Everitt, B. J., Sabino, V., and Cottone, P. (2014). High trait impulsivity predicts food addiction-like behavior in the rat. Neuropsychopharmacology 39, 2463-2472. doi: 10.1038/npp. 2014.98

Velazquez-Sanchez, C., Santos, J. W., Smith, K. L., Ferragud, A., Sabino, V., and Cottone, P. (2015). Seeking behavior, place conditioning, and resistance to conditioned suppression of feeding in rats intermittently exposed to palatable food. Behav. Neurosci. 129, 219-224. doi: 10.1037/bne0000042

Vendruscolo, L. F., Gueye, A. B., Darnaudery, M., Ahmed, S. H., and Cador, M. (2010). Sugar overconsumption during adolescence selectively alters motivation and reward function in adult rats. PLoS ONE 5:e9296. doi: 10.1371/journal.pone.0009296

Volkow, N. D., Wang, G. J., Telang, F., Fowler, J. S., Thanos, P. K., Logan, J., et al. (2008). Low dopamine striatal D2 receptors are associated with prefrontal metabolism in obese subjects: possible contributing factors. Neuroimage 42 , 1537-1543. doi: 10.1016/j.neuroimage.2008.06.002

Volkow, N. D., Wang, G. J., Tomasi, D., and Baler, R. D. (2013). The addictive dimensionality of obesity. Biol. Psychiatry 73, 811-818. doi: 10.1016/j.biopsych.2012.12.020

Voon, V., Derbyshire, K., Ruck, C., Irvine, M. A., Worbe, Y., Enander, J., et al. (2015). Disorders of compulsivity: a common bias towards learning habits. Mol. Psychiatry 20, 345-352. doi: 10.1038/mp.2014.44 
Wang, G. J., Geliebter, A., Volkow, N. D., Telang, F. W., Logan, J., Jayne, M. C., et al. (2011). Enhanced striatal dopamine release during food stimulation in binge eating disorder. Obesity 19, 1601-1608. doi: 10.1038/oby. 2011.27

Wang, G. J., Volkow, N. D., Logan, J., Pappas, N. R., Wong, C. T., Zhu, W., et al. (2001). Brain dopamine and obesity. Lancet 357, 354-357. doi: 10.1016/S0140-6736(00)03643-6

Watson, P., Wiers, R. W., Hommel, B., and de Wit, S. (2014). Working for food you don't desire. Cues interfere with goaldirected food-seeking. Appetite 79, 139-148. doi: 10.1016/j.appet.2014. 04.005

Zhang, C., Wei, N. L., Wang, Y., Wang, X., Zhang, J. G., and Zhang, K. (2015). Deep brain stimulation of the nucleus accumbens shell induces anti-obesity effects in obese rats with alteration of dopamine neurotransmission. Neurosci. Lett. 589, 1-6. doi: 10.1016/j.neulet.2015. 01.019
Ziauddeen, H., Chamberlain, S. R., Nathan, P. J., Koch, A., Maltby, K., Bush, M., et al. (2013). Effects of the mu-opioid receptor antagonist GSK1521498 on hedonic and consummatory eating behaviour: a proof of mechanism study in binge-eating obese subjects. Mol. Psychiatry 18, 1287-1293. doi: 10.1038/mp.2012.154

Conflict of Interest Statement: The authors declare that the research was conducted in the absence of any commercial or financial relationships that could be construed as a potential conflict of interest.

Copyright (c) 2017 Moore, Sabino, Koob and Cottone. This is an open-access article distributed under the terms of the Creative Commons Attribution License (CC BY). The use, distribution or reproduction in other forums is permitted, provided the original author(s) or licensor are credited and that the original publication in this journal is cited, in accordance with accepted academic practice. No use, distribution or reproduction is permitted which does not comply with these terms. 